\section{Estudo \\ cabebate}

em Cestão

Planejamento
Revista Estudo \& Debate, Lajeado, v. 26, n. 2, 2019. ISSN 1983-036X

DOI: http://dx.doi.org/10.22410/issn.1983-036X.v26i2a2019.2048

\title{
UM MODELO TEÓRICO PARA A RENDA RURAL A PARTIR DA ESTIAGEM OCORRIDA NA AMAZÔNIA EM 2005
}

\author{
Thiago Bandeira Castelo ${ }^{1}$
}

\begin{abstract}
Resumo: $\mathrm{O}$ presente artigo objetivou analisar a relação entre agricultura e extremos climáticos. Pontualmente, a forte estiagem ocorrida na Amazônia em 2005 (evento extremo e inesperado) pode ter promovido mudanças na alocaçáo de trabalho e captação de rendas das famílias rurais. Diante desse cenário, foi elaborado um modelo teórico econômico que explicasse a relação da variável climática (precipitação) e a alocação de trabalho rural. Este modelo mostra que a relação entre as variáveis é negativa, ou seja, quanto menor o volume de chuvas, maior será a procura por rendas não-rurais. Análises do Instituto Brasileiro de Geografia e Estatística (IBGE) (Censo Agropecuário de 2006) e do Sistema Integrado de Dados Ambientais (SINDA) do INPE mostraram que os estados do Acre, Rondônia e Amapá foram os mais afetados no período de seca que teve seu auge entre meados dos meses de maio, junho e julho de 2005 na regiáo amazônica e um ano depois, notou-se a diminuição da populaçáo ocupada em atividades rurais.
\end{abstract}

Palavras-chave: Amazônia. Precipitação. Renda rural.

\section{A THEORETICAL MODEL FOR RURAL INCOME FROM AS OF DROUGHT OCCURRING IN THE AMAZÔNIA IN 2005}

\begin{abstract}
The present article aimed to analyze the relationship between agriculture and climate extreme. On time, the drought that occurred in the Amazônia in 2005 (extreme and unexpected event) may have promoted changes in the allocation of labor and income capture of rural families. Against this fact, a theoretical economic model was elaborated that explained the relation of the climatic variable (precipitation) and the allocation of rural work. This model shows that the relationship between the variables is negative, that is, the lower the volume of rainfall, the greater the demand for non-farm incomes. Analyzes by the Brazilian Institute of Geography and Statistics (IBGE) (Agricultural Census 2006) and the Integrated Environmental Data System (SINDA) of INPE showed that the states of Acre, Rondônia and Amapá were the most affected in the period of drought that had its peak between mid-May, June and July 2005 in the region and one year later, it was noticed the decrease of the population occupied in agricultural activities.
\end{abstract}

Keywords: Amazônia. Precipitation. Farm Income.

1 Economista e Mestrando em Ciências Ambientais (PPGCA/UFPA). 


\section{Introdução}

A dinâmica que envolve as mudanças climáticas globais é complexa e vai além do que a simples elevação da temperatura terrestre pelo efeito estufa. As açóes de natureza antrópica têm grande participação nas mudanças climáticas como a liberação intensa de gases do efeito estufa, a derrubada de florestas tropicais e matas ciliares e a superexploração dos recursos naturais existentes, e isso, tem impactado diversos setores econômicos, principalmente a agricultura (CONTI, 2001). De fato, os pequenos e médios agricultores, estão mais propensos a sofrerem os impactos das mudanças climáticas, que incidem sobre a sua produção agrícola, afetando seu modo de vida na comunidade ou região (CONTI, 2001; FISCHER et al., 2002).

Neste sentido, diversos estudos como os de Fischer et al. (2002) e Todaro e Smith (2012) comprovam que os principais agentes afetados com as mudanças climáticas serão os pequenos e médios agricultores das regióes mais pobres do mundo. Esses agricultores geralmente têm como base para sua subsistência o plantio de culturas anuais (com queima e uso da terra) e não possuem outras fontes de renda para seu sustento.

Os países subdesenvolvidos e em desenvolvimento em regiōes como a África Subsaariana, Ásia e América Latina serão, assim, os mais afetados com os eventos extremos climáticos. Além disso, a mudança no clima tem contribuído dentre outras circunstâncias, para a migração de pessoas para as grandes cidades, e essa tem avançado a taxas exponenciais. Grande parte da explicação para esse fenômeno pode ser encontrado na estagnação das zonas rurais periféricas juntamente com as condições de vida miserável e as inadequadas práticas de produção agrícola (TODARO e SMITH, 2012).

$\mathrm{Na}$ Amazônia, floresta tropical com uma vasta biodiversidade, este problema pode ser ainda maior pelo avanço da fronteira agrícola, a frequência de incêndios florestais e consequentemente, o desmatamento. Somado a isso, existe um grande número de trabalhadores rurais dependentes da prática agrícola e das facilidades que a geografia e o clima podem oferecer a sua produção. Neste contexto, um evento que chamou atenção de pesquisadores e do governo foi a seca ocorrida no ano de 2005 na Amazônia. De acordo com o Centro de Previsão do Tempo e Estudos Climáticos - CPTEC e do Instituto Nacional de Meteorologia - INMET, foi constatado uma redução importante nos valores de precipitação na região e, ao mesmo tempo, vários rios (Rio Madeira e Rio Acre) baixaram significativamente seus níveis (CPTEC e INMET, 2005).

Isto posto, faz-se necessário estudos que comprovem como os trabalhadores rurais reagem diante das alteraçóes ambientais, a exemplo da estiagem na Amazônia, em termos de alocação de trabalho e renda. Analisar a influência da baixa precipitação sobre o setor econômico da agricultura, permite compreender como pode se dar a escolha do trabalhador rural por novas fontes de renda, haja vista que a principal fonte (renda rural), dependente das chuvas, fica comprometida. Dessa forma, espera-se que o presente trabalho contribua para outros estudos científicos que versem sobre as alteraçóes climáticas e futuras aplicações empíricas.

O presente trabalho foi divido em cinco seções. Primeiramente, uma introdução, apresentando os principais assuntos abordados na pesquisa seguido de um breve referencial 
teórico, abarcando estudos relevantes sobre as mudanças climáticas e efeitos sobre a agricultura; a metodologia que mostra as variáveis utilizadas na construçáo do modelo teórico para a renda rural; os resultados que evidenciam de que forma a estiagem impactou os estados da Amazônia e cenário agrícola da regiáo de estudo e por fim, a conclusão com recomendaçôes para futuras aplicações.

\section{Referencial teórico}

Eventos extremos como a seca na Amazônia podem ter impactos negativos sobre a produção agrícola em termos de alocação de trabalho e fonte de renda das famílias rurais. Pesquisas relacionadas às mudanças no clima e adaptação do trabalhador rural já vem sendo desenvolvidas abordando a estratégia da irrigaçáo como forma de amenizar os efeitos das mudanças climáticas (migração) pelos pequenos agricultores brasileiros, conforme analisam Cunha et at., 2013. Outras pesquisas revelam o tempo dedicado a atividades não rurais como forma de complementar a renda de comunidades rurais da Etiópia em meio a variaçóes nos padrốes de chuva na região (BEZABIH et al., 2010).

Além disso, na década de 1990, estudiosos sobre a temática do clima buscaram contribuir para o desenvolvimento de pesquisas que relacionassem as atividades econômicas com os eventos climatológicos. Nesta perspectiva, Mendelsohn et al. (1994) procurou medir o impacto econômico do clima sobre os preços da terra, usando dados sobre o clima, os preços de terras agrícolas e outras variáveis geofísicas em 3.000 municípios nos Estados Unidos (EU). Ao aplicar o modelo para um aquecimento global, o cenário mostrou um impacto significativamente menor do aquecimento sobre a agricultura dos EU. Para os autores, o aquecimento poderia ter benefícios econômicos para a agricultura. Ao utilizar a técnica Ricardiana (estimativa da importância agrícola e de outras variáveis como valor presente e valor esperado da renda rural), foi verificado o impacto do clima sobre a produtividade agrícola e disposição de dados municipais sobre insumos agrícolas.

Posteriormente a isso, outros estudos envolvendo mudanças climáticas tiveram importância significativa no campo acadêmico como Deschênes e Greenstone (2007) que ainda nos EUA, mediram o impacto econômico das mudanças climáticas na agricultura americana através da estimativa do efeito da variação aleatória ano-a-ano em temperatura e precipitação sobre os lucros agrícolas. Eles estimaram que a mudança no clima iria aumentar os lucros anuais de US\$ 1,3 bilhôes de dólares em 2002. Tal estimativa mostrou os efeitos positivos e negativos das mudanças climáticas, mesmo sendo imprecisos ou improváveis.

Trazendo a análise para o Brasil, Féres, Reis e Speranza (2010) através dos estudos anteriores de Deschênes e Greenstone (2007), publicados internacionalmente, avaliaram os efeitos das mudanças climáticas sobre a agricultura brasileira, tanto em termos de rentabilidade como de valores de terras agrícola. A avaliação foi feita a partir de dois modelos econométricos (especificação de efeitos fixos proposta por Deschênes e Greenstone (2007) e o modelo hedônico proposto por Mendelsohn et al. (1994)). Ambos os modelos foram estimados por um painel de municípios abrangendo o período entre 1970 e 1995 . Os resultados das simulaçôes sugerem que o impacto global da mudança no clima foi bastante modesto para a agricultura brasileira a médio prazo, no entanto tais impactos seriam consideravelmente mais graves no longo prazo. 
Esse estudo se valeu de uma abordagem microeconômica para identificar fatores que influenciam nas mudanças de uso da terra em estabelecimentos rurais através de variáveis como os preços dos produtos, o custo dos insumos e as características agroclimáticas. A escolha do produtor rural pela alocação de áreas foi derivada da teoria da produção e que também será utilizada no desenvolvimento do modelo do presente trabalho. De maneira geral, Féres, Reis e Speranza (2010), concluíram que o impacto das mudanças climáticas tende a se diversificar devido a heterogeneidade regional. Os impactos de longo prazo poderão ser particularmente mais críticos na região do Centro-Oeste brasileiro, resultando em perdas significativas para o setor do agronegócio brasileiro.

\section{Metodologia}

\subsection{Adaptaçáo ao modelo teórico}

Visando analisar o comportamento do trabalhador rural amazônico diante do evento extremo da seca, o presente artigo adaptou um modelo teórico econômico que atribuísse uma variável climática (considerada exógena) à maximização do lucro do produtor rural e assim, contribuir teoricamente para os estudos climáticos a partir de uma abordagem econômica. Sabendo que a produçáo do agricultor é dependente das variaçôes do clima e que ele não escolhe o nível de chuvas na regiâo, inseriu-se a precipitação como vetor climático ao modelo. Dessa forma, se baseou no modelo teórico apresentado por Groom et al., (2010), porém, agregou-se a variável climática (precipitação) que é um diferencial entre as duas pesquisas.

Groom et al. (2010) procurou observar a família rural chinesa e assim, avaliar os impactos do Programa de Conversão de Terras Inclinadas $-\mathrm{PCTI}^{2}$ na China sobre a oferta de trabalho e a produção familiar. Para tanto, os autores testaram hipóteses através de previsóes apoiadas em uma regressão. Aplicado os dados de painel, esta técnica permitiu a identificação do impacto heterogêneo do PCTI nas famílias. Foram considerados no modelo, o agregado familiar que possui preferências definidas sobre o lucro $y, l^{l}$ tempo de lazer; e um vetor de consumo $c$. A família rural é dotada de uma quantidade total de tempo T, que é alocada entre lazer $l^{l}$, em $l^{i}$ trabalho rural e $l^{\circ}$ o trabalho náo agrícola que são remunerados pelo salário $w^{\circ}$.

No entanto, no estudo em questão não busca chegar a simulação empírica, visando apenas demonstrar de que forma a abordagem microeconômica ${ }^{3}$ pode nortear as pesquisas

2 O PCTI (do inglês SLCP) foi iniciado pelo governo central, em 1999 e afirmou metas de redução de água e erosão do solo e aumentando a cobertura florestal da China e das terras marginais da produçáo agrícola. Ver em Bennetti \& Xu. China’s Sloping Land Conversion Program: Institutional Innovation or Business as Usual? [...]

3 A Microeconomia trata de questôes marginais analisando o comportamento do consumidor ou firma, onde a utilidade ou satisfação do indivíduo pode ser analogamente comparada ao lucro para o produtor. Ver em PINDYCK, R. S.; RUBINFELD, D. L. Microeconomia [...] 2005. 
com aplicabilidade na área climática e propor sugestôes para testes futuros, a fim de mostrar maiores evidências para outras regióes do Brasil.

\subsection{Levantamentos e análises}

Nesta etapa, foi realizado um levantamento detalhado sobre as mudanças climáticas globais que foi analisado em grande parte sobre a perspectiva econômica, avaliando os efeitos do clima sobre atividades econômicas importantes como a agricultura (segurança alimentar e alocação de trabalho). Partindo dessa análise, o estudo verifica o evento extremo da seca na Amazônia em 2005 através de fontes do INPE (variação do nível dos rios) e do Sistema Integrado de Dados Ambientais - SINDA/INPE que observou os níveis de precipitação para o primeiro período de cada mês (12 meses) no ano de 2005. Os dados do SINDA são colhidos pelas Plataformas de Coleta de Dados - PCDs de três em três dias de cada mês e para pesquisa foi utilizada a média por período colhido em cada mês, a fim de não superestimar a amostra e, por consequência, os resultados.

Ao mesmo tempo, a base de dados do Instituto Brasileiro de Geografia e Estatística -IBGE forneceu informaçóes importantes sobre a renda não-rural através do Censo Agropecuário de 2006 (número de estabelecimentos agropecuários - EA, população ocupada nos EA e Rendimento médio da produção rural nos EA) que foram analisadas juntamente com os dados climáticos no ano da seca em 2005. Essa análise comparativa mostrou o cenário de alguns cultivos agrícolas e mudanças no meio rural diante da estiagem de 2005, para assim, demonstrar como renda não-rural tende a se relacionar com alteraçóes da precipitação.

O SINDA conta com modernas PCDs ou Estaçōes Ambientais Automáticas que surgiram da necessidade de inúmeras empresas e instituiçóes obterem regularmente informaçóes colhidas em lugares remotos ou espalhadas por uma região muito extensa. As informações colhidas são de natureza meteorológicas (temperatura, pressão, direção e velocidade dos ventos, umidade, etc.), sendo utilizadas para previsão de tempo e estudos climáticos. Por meio desses dados é possível preventivamente alertar governantes e empresas públicas, responsáveis por administrar reservatórios, sobre as alteraçóes do nível da água, evitando assim, a falta de água num período de seca (comprometendo a geração de energia elétrica) extrema. $\mathrm{O}$ alerta também pode ser útil para um período de cheia (chuvas abundantes), onde as comportas precisam ser abertas, inundando as margens dos rios. As PCDs são em sua maior parte destinadas às aplicaçóes com satélites e munidas com células solares e baterias para o seu suprimento de energia (SINDA, 2005).

\section{Resultados e discussão}

\subsection{A estiagem de 2005 e a agricultura na Amazônia}

De acordo com os dados colhidos no SINDA, pode-se verificar a baixa precipitação ocorrida no ano de 2005 ao longo da temporada mais chuvosa, ou chamado inverno amazônico entre meados dos meses de maio, junho e julho. Em alguns estados da Amazônia legal teve-se zero de precipitação no primeiro período dos meses da estação, como também 
se obteve mais de $1.000 \mathrm{~mm}$ em média para a mesma estação, exemplo do Amapá. No entanto, o volume de chuvas registrado foi abaixo da média anual de $3.112 \mathrm{~mm}$ (INMET, 2016) (Figura 1).

Figura 1. Níveis de precipitação para os estados da Amazônia ao longo do ano de 2005

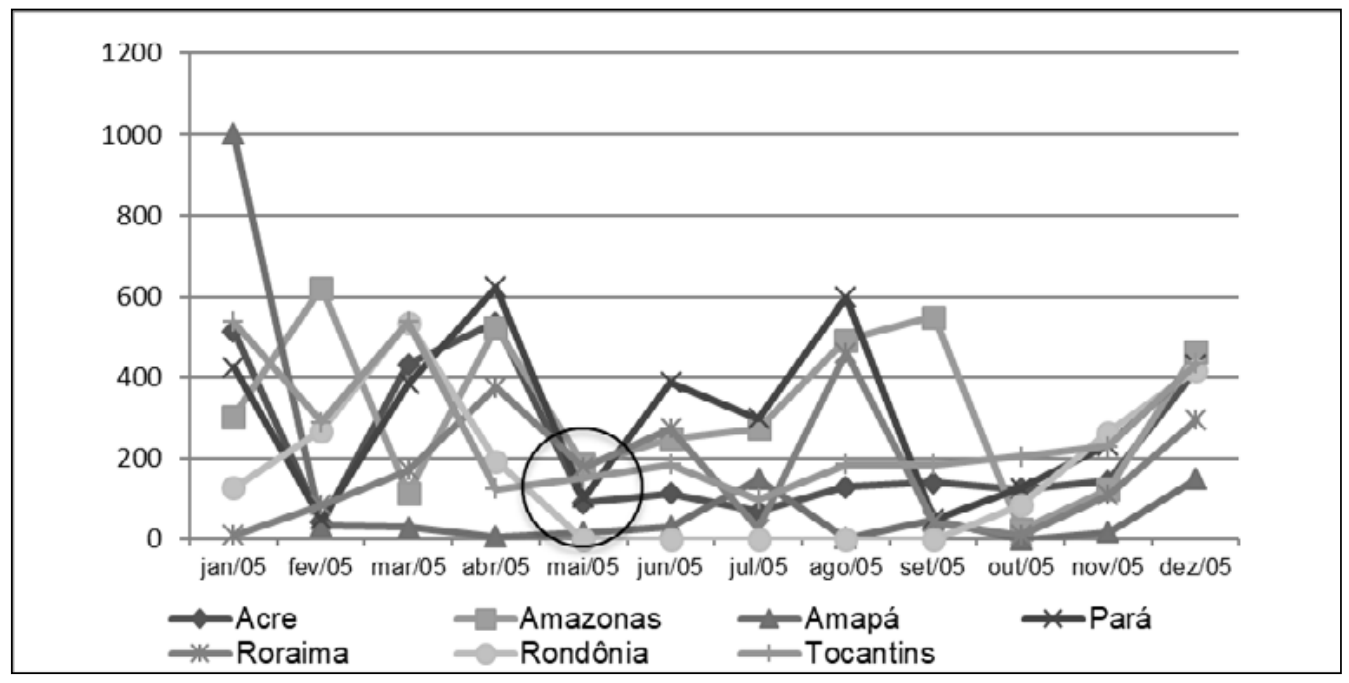

Fonte: Do autor, a partir de dados da pesquisa, 2016.

No geral, os estados da Amazônia legal ${ }^{4}$ ficaram abaixo dos $600 \mathrm{~mm}$ de água entre os meses de maio e junho, período em que a seca assolou mais fortemente a região. Marengo et al., (2008) afirmam que depois do mês de abril em 2005, foram notadas anomalias de precipitação em grande parte do sul e oeste da Amazônia da Bolívia, do Brasil, e Peru e, em particular, na Bacia do Rio Solimóes. A partir de maio a setembro de 2005, anomalias negativas foram percebidas, chegando a menos de $100 \mathrm{~mm}$ ao longo ocidental Amazônia. Durante o mesmo período da Amazônia Central e Oriental, chuvas acima do nível normal ocorreram de formas isoladas.

Ao mesmo tempo, o cenário do agricultor da Amazônia, foi identificado através do Censo Agropecuário e Pesquisa Agrícola Municipal em termos de rendimento médio da produção, no qual o mesmo, pouco variou no ano de 2005 em relação aos outros anos analisados. O rendimento da produção nos EA se manteve estável ao longo do período, sendo que a batata-doce foi a cultura que apresentou maior rendimento nos EA (Figura 2).

4 A Lei 1.806 de 06 de janeiro de 1953 criou o conceito da Amazônia Legal, na qual dispóe sobre o Plano de Valorizaçáo Econômica da Amazônica, cria a superintendência da sua execuçáo e dá outras providências. 
Figura 2. Rendimento total da produçáo agrícola de 10 culturas dos estados da Amazônia Legal entre os anos de 2001 a 2008

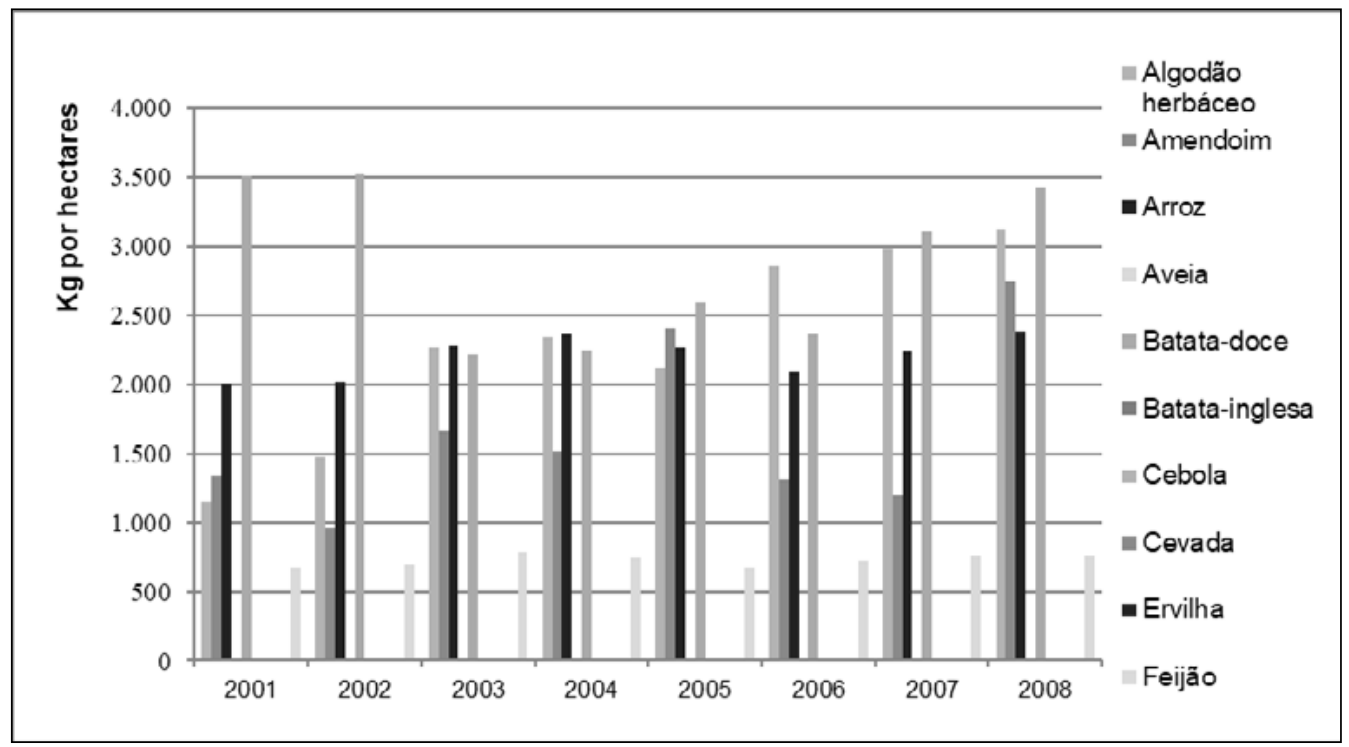

Fonte: Do autor, a partir de dados da pesquisa, 2016.

Em termos de rendimento, a produção dos agricultores da região amazônica se manteve estável ao longo dos anos analisados. $\mathrm{O}$ rendimento total da produção das culturas não foi agregado ao modelo teórico, pois ele tem ligação com o fator terra, e esta, não é uma variável de interesse da presente pesquisa, que visou apenas observar o comportamento alocativo do trabalho e por consequência da renda em relaçáo a precipitação - evento exógeno e que não é escolhido pelo produtor, sendo um evento inesperado.

Posteriormente, foi identificado através do Censo agropecuário de 2006 que de 1995 a 2006, último levantamento feito pelo IBGE, a população ocupada em atividades agrícolas nos EAs caiu de aproximadamente 1.877 mil para quase 1.600 mil pessoas juntamente com um leve aumento do número de EAs (Figura 3). 
Figura 3. Comportamento da população ocupada nos EAs da regiấo Norte em relação ao número de EAs nos levantamentos dos Censos agropecuários do IBGE (1970-2006)

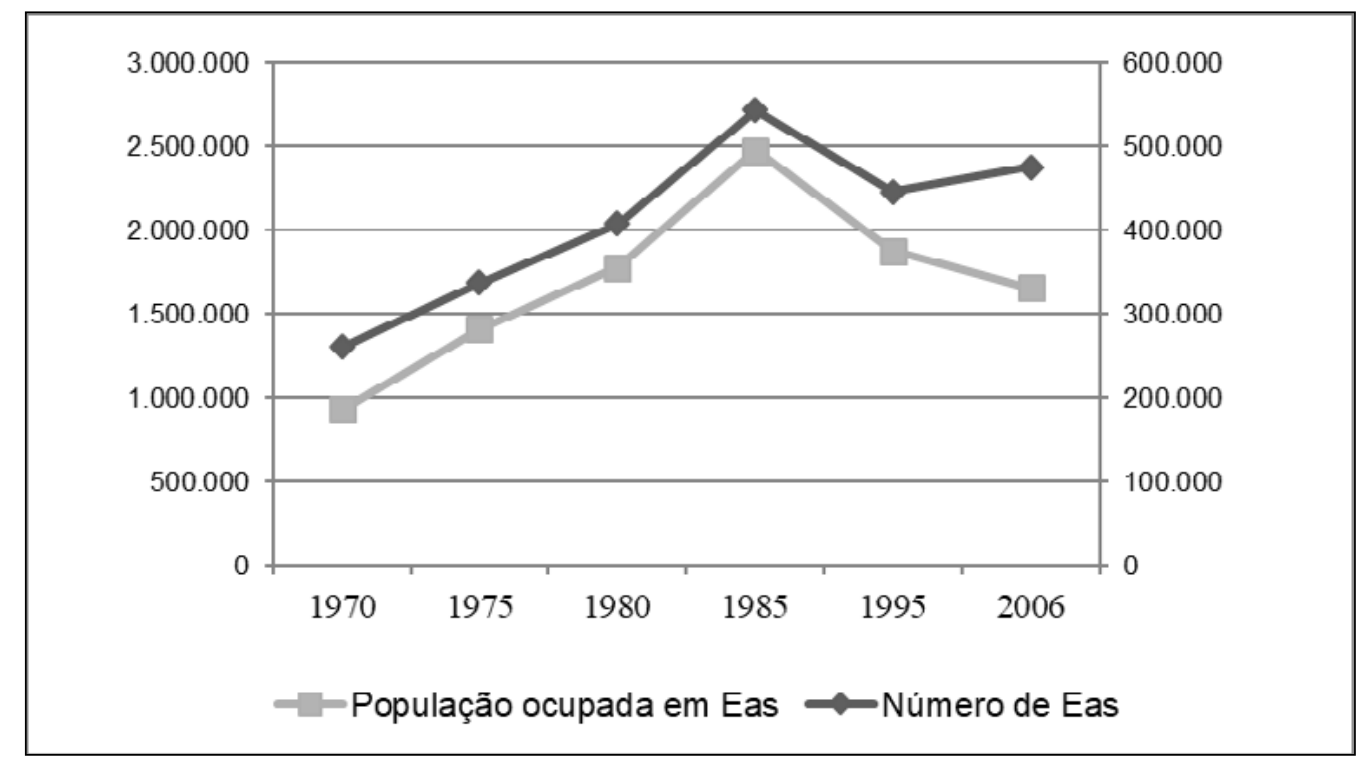

Fonte: Do autor, a partir de dados de pesquisa, 2016.

A relação de EAs com a população ocupada mostra uma elevaçáo da concentração de terras na Amazônia. Dentre as condiçóes que podem levar a queda do número de pessoas ocupadas nos EAs, estão a piora nas condições socioeconômicas, modernização tecnológica da agricultura (HESPANHOL, 2013) somada as alteraçôes nas condiçóes climáticas.

Seria inadequado afirmar que somente o fator clima influencia na ocupação das pessoas em atividades rurais haja vista que outras variáveis (migração urbano-rural, elevação de preços, períodos de safra agrícola etc.) podem ter tido impacto sobre a queda ocupacional dos EAs. No entanto, o modelo proposto neste trabalho pode ser útil para verificar como a variável climática pode ser agregada em estudos sobre alocação de trabalho e renda rural, neste caso, a variável precipitação. Ainda sobre essa discussắo, o Quadro 1 mostra os principais aspectos em relação ao pessoal ocupado nos EAs. Mesmo em EAs, pessoas que não trabalhavam em atividades agropecuárias residiam na zona rural $\mathrm{e}$, a variação neste número de pessoas pode estar ligada aos efeitos exógenos da precipitação. 
Quadro 1. Aspectos do pessoal ocupado em atividades agrícolas na Amazônia segundo o Censo Agropecuário de 2006

\begin{tabular}{|l|r|}
\hline \multicolumn{2}{|c|}{ Principais aspectos em relaçáo ao pessoal ocupado } \\
\hline Residiam no estabelecimento & 1.266 .268 \\
\hline Recebiam salário & 51.548 \\
\hline Trabalhavam somente em atividades não-agropecuárias & 24.919 \\
\hline
\end{tabular}

Fonte: SIDRA/IBGE, 2006.

\subsection{O extremo climático na Amazônia}

O cenário de mudanças globais com relação ao clima tem preocupado governos e especialistas de diferentes áreas da ciência (Meio Ambiente, Economia, Biologia entre outros). Os eventos extremos têm se tornado comuns em diversas regióes do planeta e impactado o setor econômico da agricultura por meio da produçáo de alimentos no elo primal da cadeia produtiva $^{5}$. Neste sentido, um grande evento ocorrido em 2005 foi a estiagem que assolou a Amazônia brasileira. Estudos feitos pelo Centro de Previsão do Tempo e Estudos Climáticos - CPTEC juntamente com o Instituto Nacional de Meteorologia - INMET analisaram os principais fatores para o evento da seca em 2005.

Os levantamentos realizados pelos institutos de pesquisa verificaram que possivelmente a seca de 2005 poderia estar relacionada ao comportamento médio da temperatura da superfície do mar - TSM naquele período na Bacia do Atlântico Tropical Norte. Neste ano, ocorreu um movimento ascendente do ar que normalmente ocorre no Atlântico Tropical Norte, e que se tornou mais intenso, dada a zona de convergência intertropical no Hemisfério Norte. A intensificação da circulação atmosférica fez com que os movimentos descendentes especialmente sobre o sudoeste da Amazônia se tornassem mais intensos do que a média, dificultando a formação de nuvens e, portanto, de chuvas na região. Outros aspectos especulados na época foi o grande período de estiagem vivenciado na região, ocasionando um efeito local que contribuiu mais ainda para a diminuição das chuvas. Este efeito seria uma diminuição da reciclagem de vapor d'água pela vegetação devido à própria estiagem, implicando um feedback positivo, reduzindo possivelmente as chuvas locais (CPTEC; INMET, 2005).

Além disso, a queima de biomassa poderia possivelmente adiar o início da estação chuvosa. No entanto, não houve evidências de que esta seca seja um indicador de mudanças climáticas associadas ao desmatamento ou aquecimento global. Ainda assim, os efeitos das mudanças climáticas vivenciadas na região ocasionaram alteraçóes no padrão de vida de

5 A cadeia produtiva em síntese se resume na colheita da matéria prima, armazenamento, produção e distribuição ao consumidor final, sendo que o produtor rural está no início da cadeia - responsável pela colheita do produto agrícola a ser processado pela indústria agroindustrial e alimentícia. Ver em VIAL, L. A. M.; SETTE, T. C.; SELLITTO, M. A. Cadeias produtivas - foco na cadeia produtiva de produtos agrícolas. In: III Encontro de Sustentabilidade em Projeto do Vale do Itajai [...] 2009. 
muitas famílias locais, que tiveram sua fonte de renda (agricultura) afetada com a seca. A diminuição da precipitação inibe o aumento da produção agrícola que tem como insumo básico e natural a água advinda das chuvas. Marengo et al. (2008) afirmam que a seca deixou milhares de pessoas com falta de comida, causou problemas com transporte fluvial, agricultura, geração de energia hidrelétrica, e também afetou direta e indiretamente as populaçóes que vivem as margens dos rios da região. Ao mesmo tempo, com a seca nas regiōes de floresta densa, eclodiram incêndios, prejudicando centenas de milhares de hectares de floresta e afetou a saúde humana.

\subsection{A Construçáo do Modelo teórico}

Diante do cenário apresentado na coleta de dados, um modelo teórico foi elaborado na tentativa de explicar o comportamento da renda do produtor rural diante da variação da precipitação no período da seca ocorrida na Amazônia em 2005. Buscando otimizar a produção agrícola do trabalhador mediante os efeitos da baixa precipitação, o modelo foi pensado para o cenário da seca na Amazônia ocorrida em 2005 e se fez uso da mesma intuição de Groom et al. (2005) que modelou seguindo alguns princípios microeconômicos das teorias do consumidor e da firma ${ }^{6}$. No entanto, foi inserida a variável climática $p$, que indicará a precipitação no período analisado. Assim, considera-se uma família rural cujas preferências são definidas pelo nível de receita $y$, tempo destinado ao lazer, um vetor de consumo determinante $c$. A família decide alocar o tempo T entre três atividades: lazer (LZ), o trabalho rural $\left(l^{n}\right)$ e trabalho não-rural $\left(l^{p f f}\right)$, de acordo com a equação (1) de modo que,

$$
\mathrm{T}=\mathrm{LZ}+l^{n}+l f^{f f}
$$

Assume-se que o salário não-rural é exógeno e denotado por $w^{\text {off }}$, e que a precipitação ocorrida no período é exógena, pois o agricultor não escolhe o nível de chuvas (denotado por $p$ ).

A família rural tem uma quantidade de terra (fixa) para sua produção e sofre influência da precipitaçáo (volume de chuvas) e do trabalho rural no seu estabelecimento, o que pode ser representada pela função de produção $\mathrm{p}^{*} \mathrm{q}\left(l^{n n}, p\right)$, onde q é a quantidade de produção, o $l^{o n}$ é quantidade de trabalho alocado para atividades rurais e o $p$ é a variável precipitação.

6 A teoria do consumidor busca descrever como os consumidores tomam decisóes de compra através da maximização de sua utilidade ou satisfação. Já a teoria da firma analogamente a teoria do consumidor também busca maximizar (produção) de acordo com seus recursos disponíveis e isso, pode se dá pela minimização dos custos. Uma discussão conceitual sobre as teorias na perspectiva do bem-estar (social e econômico) pode ser vista em Giacomelli et al. Da economia tradicional do bem-estar à Abordagem das Capacitaçôes e a importância da equidade em saúde para o desenvolvimento humano. Nova Economia [...] 2017. 
A tecnologia de produção segue as hipóteses-padrão adotados pela literatura: $Q_{1}$ $\left(l^{n}, p\right)>0, \mathrm{q}_{2}\left(l^{o n}, p\right)>0, \mathrm{Q}_{11}\left(l^{n}, p\right)<0$ e $\mathrm{q}_{22}\left(l^{o n}, p\right)<0$, onde o índice i refere-se a derivada parcial em relaçáo ao argumento i da função ${ }^{7}$.

A função de utilidade doméstica rural $\mathrm{U}(y, \mathrm{lz}, \mathrm{c})$ é côncava e duas vezes diferenciável. A renda domiciliar total é dada pela soma da receita rural e renda não-rural, e pode ser representada por $y=\mathrm{p}^{*} \mathrm{q}\left(l^{o n}, p\right)+w^{\text {off. }}$. loff. A variável agroclimática é $p$ e o tempo destinado ao lazer é expresso por $\mathrm{lz}=\mathrm{T}-l^{o n}-l^{\circ f f}$. Assim, o problema de otimização enfrentado pela família rural pode ser expressa por:

$$
\begin{gathered}
\operatorname{Max}_{l^{a}, l^{n}} U\left(p\left(l^{a}, p\right)+w^{o f f} l^{o f f}, T-l^{a}-l^{o f f}, c\right) \\
l^{a} \geq 0 \\
l^{o f f} \geq 0
\end{gathered}
$$

Considerou-se o caso em que as famílias rurais irão alocar tempo tanto para atividades rurais como para atividades não-rurais. Neste caso, as condiçóes de primeira ordem do problema de otimização (1) são indicadas pelas seguintes expressões:

$$
\begin{aligned}
& \mathrm{dU}_{1} / \mathrm{d} l^{o n}=\mathrm{U}_{1}(.) w^{o f f}-\mathrm{U}_{2}(.)=0 \\
& \mathrm{dU}_{1} / \mathrm{d} l o f f=(.) \mathrm{pq}_{1}(.)-\mathrm{U}_{2}(.)=0
\end{aligned}
$$

onde $U_{1}$ (.) é a utilidade marginal da renda, $U_{2}$ (.) é a utilidade marginal do lazer. Considerou-se que o agricultor usa toda a terra disponível, sendo fixa. Sendo assim, a partir das condições 2 e 3 verifica-se que:

$$
w^{o f f}=\mathrm{PQ}_{1}\left(l^{o n}, p\right)
$$

A condição (4) indica que a família rural, fazendo uso de toda a terra disponível tem sua produtividade marginal de suas atividades rurais igualada ao salário pago por atividades não-rurais.

A partir das condições de otimização, pode-se afirmar a seguinte proposição:

Proposição: um aumento da renda não-rural está condicionado a precipitação e a oferta de trabalho rural na medida em que $\mathrm{L}^{*}=l^{n}+l^{o f f}$.

Prova: Primeiro mostra-se que, dada a complementaridade entre o trabalho agrícola e uso agrícola, um aumento (redução) do volume de chuvas implica em aumentar (diminuir) o trabalho agrícola e por intuição, alocar o trabalhador em atividades não-rurais.

Assim, ao aplicar o teorema da função implícita para $p$ e $l^{o n}$, tem-se:

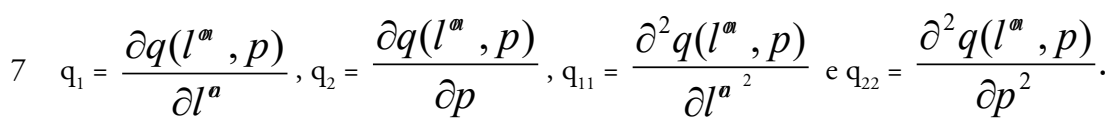




$$
\frac{d l}{d p}^{\text {on }}=\frac{q 21\left(l^{\text {on }}, p\left(l^{\text {on }}\right)\right)}{q 22\left(l^{\text {on }}, p\left(l^{\text {on }}\right)\right)}>0
$$

Em outras palavras, um aumento (redução) em trabalho não-rural está condicionado ao aumento (diminuição) da precipitação.

Ao tomar o diferencial total da equação (5), mantendo a constante $p$ variável exógena, temos:

$$
\mathrm{d} w^{o f f}=\mathrm{p}\left[\mathrm{q}_{11}\left(l^{o n}, p\right) \mathrm{d} l^{o n}+\mathrm{q}_{12}\left(l^{o n}, p\right) \frac{d l o n}{d p} d l^{o n}\right] .
$$

Portanto, um aumento na renda não-rural implica uma produtividade marginal mais elevado associado a atividades agrícolas, que é obtido através da redução $l^{n}$ e $p$.

Este resultado pode ser explicado pelo maior custo de oportunidade associado ao

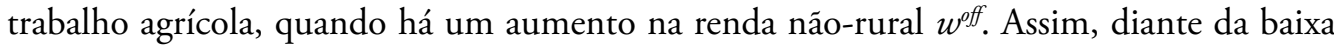
precipitação, os agricultores irão alocar menos tempo para o trabalho agrícola, reduzindo assim $l^{n}$. Neste sentido, pode-se propor o seguinte corolário:

Como $T=l^{o n}+l^{o f f}$

Logo, loff $=T-l^{\circ n}$

Dado que:

$\frac{d l}{d p}^{\text {on }}>0 \mathrm{e}$

$\frac{d l}{d p}^{\text {off }}=\frac{d l\left(T-l^{\text {on }}\right)}{d p}$ com $T=0$ (se todos os trabalhadores rurais se ocupassem nas atividades rurais e não-rurais) pode-se ter:

$-\frac{d l}{d p}^{\text {on }}$ ou seja, $-\frac{d l}{d p}^{\text {on }}<0$

E assim, a correlação negativa pode ser encontrada:

$$
\frac{d l}{d p}^{\circ f f}<0
$$

Fica demostrado então, a relação existente entre renda não-rural e precipitação de acordo com o corolário afirmado neste modelo. $\mathrm{O}$ resultado obtido vem ao encontro de estudos que analisam a alocação de trabalho e rendas não rurais, a exemplo de Jessoe et al. (2016), que traz evidências sobre os efeitos das alteraçóes climáticas sobre a alocação de trabalho. Ao utilizar variáveis climáticas, os autores descobriram que o calor extremo foi o mais significativo para a busca por fontes de renda não rurais. Concomitantemente, Allahyari et al. (2016) sugere que a tomada de decisão dos agricultores em relação a alocação de trabalho está fortemente relacionada as variabilidades climáticas de temperatura e 
precipitação e Emerick (2018) mostrou que o efeito exógeno na produtividade causado pela precipitação leva a um aumento por rendas não rurais.

Os estudos citados corroboram a importância do impacto das alteraçóes climáticas sobre a dinâmica laboral do meio rural, no entanto, os estudos tendem a incorporar o fator terra em seus postulados. Ao mesmo tempo, os estudos não consideram a precipitação como fator principal para mudanças na renda rural, fazendo parte de uma análise secundária. Emerick (2018), em particular, destacou em sua pesquisa a produtividade do meio rural, determinando que a elevação do volume de chuvas gera um aumento na busca por fontes de renda não rurais. Essa conclusão diverge da apresentada na atual pesquisa pois de acordo com o corolário, a relação das chuvas com a renda não rural é inversamente proporcional.

\subsection{Mudanças climáticas globais e a agricultura}

Estudos do I grupo de trabalho (IPCC, 2013) proporcionaram uma contribuição importante ao relatório de avaliação do quinto painel intergovernamental sobre mudanças climáticas, oferecendo observaçôes do sistema climático baseadas em mediçóes diretas e de sensoriamento remoto por satélites e outras plataformas. Para tanto, foram realizadas observaçóes globais em escala da era instrumental que começou em meados do século XIX para a temperatura, precipitação dentre outras variáveis com conjuntos mais abrangentes e diversificadas observaçóes disponíveis para o período de 1950 em diante.

Conforme demonstra a Figura 4, a atmosfera e o oceano têm aquecido, a quantidade de neve e gelo tem diminuído, o nível do mar subiu, e as concentrações de gases de efeito estufa têm aumentado, aumentando a temperatura em grande parte do globo terrestre. Desta forma, embora a influência humana sobre o sistema climático seja significativa, no relatório é ressaltado a evidência de que a concentraçáo de gases de efeito estufa na atmosfera tem sido determinadas por forças radiativas positivas além no natural aquecimento observado no sistema climático (Figura 4). 
Figura $4^{8}$. Mudança observada na temperatura da superfície entre os anos de 1901 a 2012.

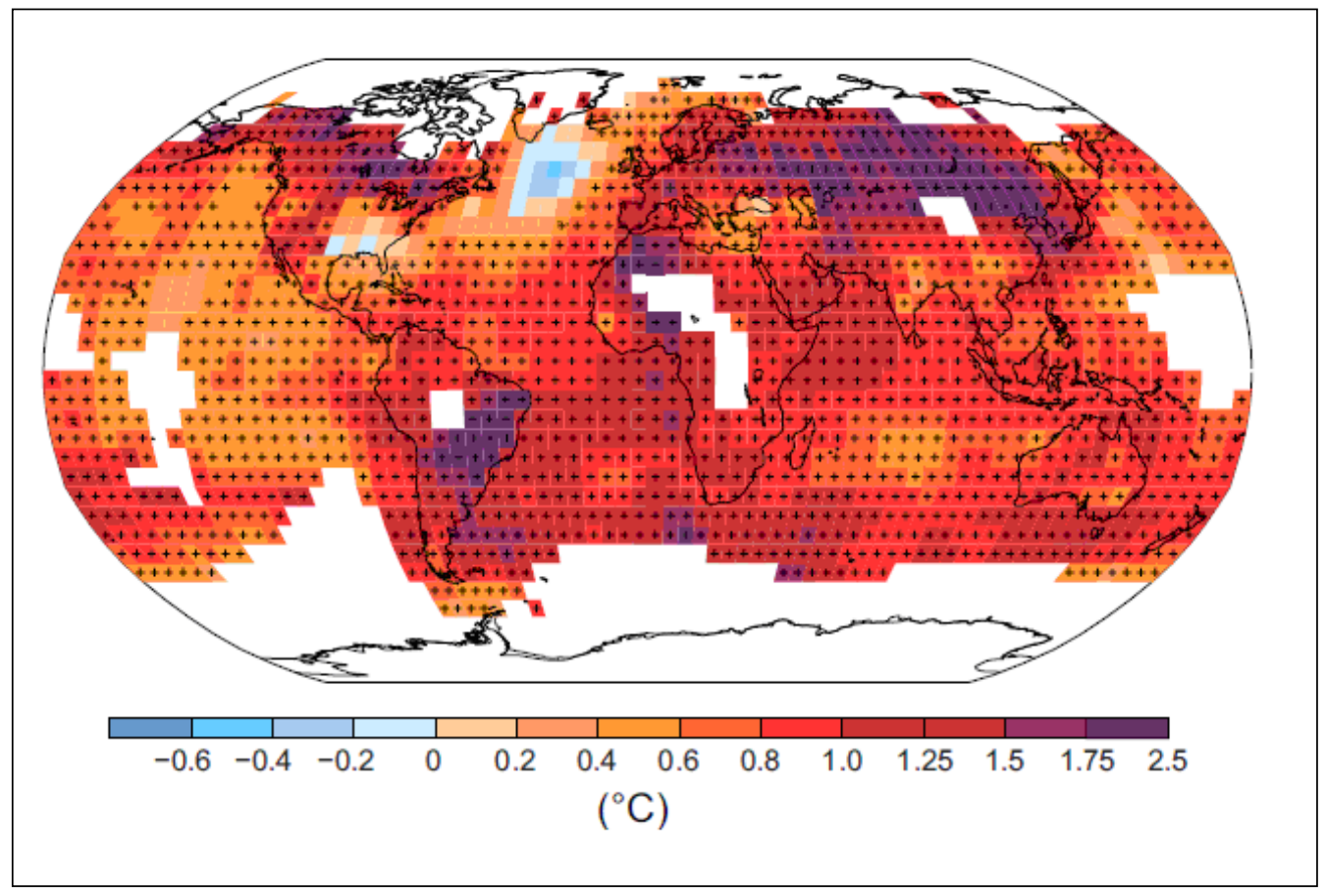

Fonte: IPCC, 2013.

É importante ressaltar, portanto, que o estudo do IPCC considerou que a capacidade dos agricultores de se adaptar as mudanças climáticas não é susceptível de pôr em risco a produção de alimentos mundial. Embora, a produção mundial de todos os bens e serviços podem diminuir, se a mudança climática agravar o suficiente no que se refere a expansão das terras agrícolas.

As mudanças climáticas não são homogêneas ao redor do mundo, logo, a produção agrícola pode aumentar em áreas árticas e alpinas, mas diminuir em áreas tropicais e temperadas. No que se refere aos impactos das mudanças climáticas na agricultura e suas limitaçóes, Darwin et al. (1995) analisaram as condiçóes para adaptação econômica para o mundo. Em primeiro lugar, considerou-se a substituição entre bens intermediários ou entre fatores intermediários e primários não foi permitida. $\mathrm{O}$ que significa que os aumentos de

8 (a) Observação de anomalias de temperatura de superfície média global combinada da terra e do oceano, 1850-2012 a partir de três conjuntos de dados. Painel superior: valores médios anuais. Painel inferior: valores médios de décadas, incluindo a estimativa de incerteza para um conjunto de dados (preto). As anomalias são relativas à média de 1961-1990. (b) Mapa da mudança observada de temperatura da superfície 1901-2012 derivada de tendências de temperatura determinadas por regressáo linear a partir de um conjunto de dados (linha laranja no painel a) As tendências foram calculadas onde a disponibilidade de dados permitiu uma estimativa sólida (isto é, apenas para as caixas de grelha com mais do que $70 \%$ registos completos e mais do que $20 \%$ de disponibilidade dos dados do primeiro e últimos 10\% do período de tempo) (IPCC, 2013). 
fertilizantes não podem ser utilizados para compensar as perdas de produtividade provocadas pelo clima.

Neste estudo, considerou-se também o valor de mercadoria da terra. $\mathrm{O}$ valor de amenidades ambientais da terra não está incluído. Isso significa, por exemplo, que os valores de madeira serrada, celulose e commodities florestais semelhantes são controladas, mas os valores de melhorias relacionadas com as florestas no ar e qualidade da água não estão. Ainda no que se refere a regiāo "resto do mundo" inclui a América Latina, África, Ásia ocidental, muito do sul da Ásia, na antiga União Soviética e os países da Europa fora Comunidade da Europa (CE) (DARWIN et al., 1995).

Assim, pode-se dizer que é difícil obter informaçóes precisas sobre como os impactos econômicos das mudanças climáticas (principalmente de eventos extremos como secas e inundaçóes) seriam distribuídos para uma grande parte do mundo. No entanto, algumas adaptaçóes potenciais por parte do produtor rural podem amenizar os efeitos negativos da mudança no clima como: reflorestamento, manutenção das áreas de preservação permanente e introdução de novas raças de gado. Além disso, os custos de conversão física da terra em outros usos, por exemplo, para a construçáo de estradas, podem ser amortizados diante das distorçôes econômicas atuais, corrigindo as externalidades, na forma de subsídios e tarifas.

\section{Conclusáo}

Para esse estudo, analisou-se a estiagem ocorrida na Amazônia em 2005 que serviu como cenário para a formulação de um modelo teórico e econômico que mostrasse a relação existente entre uma variável climática (precipitação) e a alocação de trabalho por meio da renda não-rural. $\mathrm{O}$ modelo construído é considerado adequado para nortear pesquisas que versam sobre a Economia Agrária, Clima e Meio Ambiente em outras regióes do Brasil e do mundo.

Investigaçóes científicas têm mostrado que a agricultura é uma atividade econômica das mais afetadas com as mudanças no clima, sendo de vital importância para as comunidades rurais que dependem da produção para sua subsistência, onde também pode obter renda mediante a venda dos produtos agrícolas. Na Amazônia, os dados coletados do SINDA mostraram que a baixa precipitaçâo ocorrida em 2005 teve maior impacto entre os meses de maio e julho e os estados do Acre, Rondônia e Amapá foram os mais afetados e, no ano seguinte, houve uma queda da população ocupada em atividades agrícolas nos EAs.

A estiagem ocorrida na Amazônia é um bom exemplo de como eventos extremos podem afetar o modo de vida de milhares de pessoas nas mais diversas localidades do mundo. Entender os fatores para a ocorrência de tais eventos é fundamental para a prevenção de catástrofes "quando possíveis" de serem evitadas. Os eventos podem ser naturais ou antrópicos, ou seja, causados pelo homem, no entanto, eventos como o ocorrido em 2005 não tem comprovaçóes científicas de que foi influenciada pelas açóes do homem, a exemplo da emissão de gases do efeito estufa. Dessa forma, pode-se falar de um evento natural, influenciado em boa parte pelas correntes atmosféricas vindas do oceano como citado em Marengo et al. (2008). 
Sugestôes referentes a futuras aplicações empíricas de modelo teórico econômico são feitas no sentido de apresentar evidências para regióes do planeta ainda não testadas, como a região Amazônica. Para finalizar, é importante ressaltar que o produtor rural sempre buscará maximizar sua produção no objetivo de atingir seu máximo lucro e limitações impostas ao seu lucro pelas alteraçôes climáticas precisam ser mais bem analisadas para que se compreenda como a renda não rural poderá compensar a redução do lucro esperado pelas famílias rurais.

\section{Referências}

ALLAHYARI, M. S.; GHAVAMI, S.; MASULEH, Z. D.; MICHAILIDIS, A.; NASTIS, S. A. Understanding Farmers' Perceptions and Adaptations to Precipitation and Temperature Variability: Evidence from Northern Iran. Climate, vol. 4, 58p., 2016.

BEZABIH, M.; GEBREEGZIABHER, Z.; GREBREMEDHIN L.; KÖHLIN G. Participation in Off-Farm Employment, Rainfall Patterns, and Rate of Time Preferences: The Case of Ethiopia. Environment for Development. Discussion Paper. Series August 2010, p. 10-21.

CENTRO DE PREVISÃO DO TEMPO E ESTUDOS CLIMÁTICOS (CPTEC), 2005, Infoclima, São Paulo.

CONTI, J. B. Consideraçóes sobre as mudanças climáticas globais. Geografia, São Paulo, no 4. P. 6-9, 2001.

CUNHA, D. A. da; COELHO, A. B.; FÉRES, J. G.; BRAGA, M, J.; SOUZA, E. C. de. Irrigação como Estratégia de Adaptação de Pequenos Agricultores às Mudanças Climáticas: aspectos econômicos. RESR, Piracicaba, São Paulo, vol. 51, no2, p.369-386, 2013.

DARWIN, R.; TSIGAS, M.; LEWANDROWSKI, J.; RANESES A. World Agriculture and Climate Change Economic Adaptations. Agricultural Economic Report, Washington, DC - U.S. Department of Agriculture, no 703, 1995.

DESCHÊNES O.; GREENSTONE M. The Economic Impacts of Climate Change: Evidence from Agricultural Output and Random Fluctuations in Weather. The American Economic Review. vol. 97, 2007.

EMERICK, K. Agricultural productivity and the sectoral reallocation of labor in rural India, Journal of Development Economics, Elsevier, vol. 135, p. 488-503, 2018.

FÉRES, J.G.; REIS E.; SPERANZA, J. Assessing the Impact of Climate Change on the Brazilian Agricultural Sector. In: Anais do $\mathbf{4 6}^{\circ}$ Congresso da Sociedade Brasileira de Economia, Administraçáo e Sociologia Rural, Rio Branco, Acre, 2008. 
FISCHER G.; MAHENDRA, S.; VELTHUIZEN, H. V. Climate Change and agricultural Vulnerability. International Institute for Applied Systems Analysis as a contribution to the World Summit on Sustainable Development, Johannesburg, 2002.

GROOM B.; GROSJEANY P.; KONTOLEONZ, A.; SWANSON T.; ZHANG S. Relaxing rural constraints: a 'win-win' policy for poverty and environment in China? Oxford Economic Papers, no 62, p.132-156, 2010.

HESPANHOL, R. Ap. de M. CAMPO E Cidade, Rural e Urbano no Brasil Contemporâneo. Mercator, Fortaleza, vol. 12, no 2, p103-112, 2013.

INSTITUTO BRASILEIRO DE GEOGRAFIA E ESTATÍSTICA (IBGE), vários anos. Anuários Estatísticos, Censos Agropecuários.

INSTITUTO NACIONAL DE METEOROLOGIA (INMET), 2005, Acesso a Informaçáo, Brasília.

INSTITUTO NACIONAL DE METEOROLOGIA (INMET), 2016, Monitoramento Climático, Brasília.

INTERGOVERNMENTAL PANEL ON CLIMATE CHANGE (2013). Climate Change 2013. The Physical Science Basis Working Group I Contribution to the Fifth Assessment Report of the Intergovernmental Panel on Climate Change. WMO, UNEP - University of Bern, Suiça.

JESSOE, K., MANNING, D. T., TAYLOR, J. E. Climate Change and Labour Allocation in Rural Mexico: Evidence from Annual Fluctuations in Weather. The Economic Journal, vol.128, p.230-271, 2017.

MARENGO J. A; NOBRE C. A.; TOMASELLA J. The Drought of Amazonia in 2005. Journal of Climate. Vol. 21, p.495-516, 2008.

MENDEILSOHN R.; NORDHAUS W. D.; SHAW D. The Impact of Global Warming on Agriculture: A Ricardian Analysis. The American Economic Review. vol. $84 \mathrm{n}^{\circ} 4$, p.753-751, 1994.

SISTEMA INTEGRADO DE DADOS AMBIENTAIS (SINDA), 2005, Dados Hidrológicos, Brasília.

TODARO M. P.; SMITH, S. C. Economic development. 11th ed. United States of America, 803p, 2012. 